\title{
A simple Demonstration of the Wiener-Khinchin Theorem using a Digital Oscilloscope and Personal Computer
}

\author{
Se-Min Jung ${ }^{\dagger}$ \\ Department of New Material Physics, College of Natural Science, Dong-A University, 840 Hadan-dong, Saha-gu, Busan 604-714, Korea
}

(Received July 16, 2013; Revised manuscript August 26, 2013; Accepted August 26 2013)

\begin{abstract}
The Wiener-Khinchin theorem ${ }^{[1,2,3]}$, which means that the autocorrelation function of a signal corresponds to the power spectrum of the signal, is very important in signal processing, spectroscopy and telecommunications engineering. However, because of needs for some relatively expensive equipments such as a correlator and the signal processing system, its demonstration in most undergraduate class is not easy so far. Recently, digital oscilloscopes whose functions can be replaced foresaid equipments are marketed with development of digital engineering. In this paper, a simple demonstration of the theorem is given by a digital storage oscilloscope and a personal computer with its theoretical background. The reason that deals again with this theorem which has been introduced in 1930 is that it has been not well informed yet to us and theoretical background of the demonstration is directly introduced from its driving process. Through deriving process of the theorem, some extended physical meanings of the impedance, power, power factor, Wiener spectrum, linear system response and, furthermore, basic idea of the Planck's quantization in the black body theory reveal themselves naturally. Hence it can be referred to lectures in general physics, modern physics, spectroscopy and material characterization experiment.
\end{abstract}

Keywords: Wiener-Khinchin theorem, Digital oscilloscope, Demonstration, Wiener spectrum

OCIS codes: (000.2060) Education; (000.2190) Experimental physics; (000.2658) Fundamental tests

\section{디지털 오실로스코프에 의한 Wiener-Khinchin 정리의 시현 정세민 ${ }^{\dagger}$ \\ 동아대학교 자연대학 신소재물리학과 \\ (ㅇ) 604-714 부산시 사하구 하단 2동 840 번지}

(2013년 7월 16일 받음, 2013년 8월 26일 수정본 받음, 2013년 8월 26일 게재 확정)

\begin{abstract}
위너-킨친 정리(Wiener-Khinchin) ${ }^{[1,2,3]}$ 는 어떤 신호의 자기상관 함수(Autocorrelation)가 그 신호의 일율 분광띠(Power Spectrum) 에 해당됨을 보이는 것으로써, 분광학 및 통신 공학에서 신호 처리와 관련된 매우 중요한 정리이다. 학부 실험실에서 이 정리를 시현하려면 상관기(Correlator)와 신호 처리 장비와 같은 비교적 고가의 장비가 요구되므로, 정리의 시현이 용이하지 않다. 근래에 들어 디지털 공학의 발전과 함께 보급되고 있는 디지탈 오실로스코프들은 측정 결과의 수치화와 그들에 관한 연산 기능이 포함 되어 있어, 이 정리를 간단히 시현시킬 수 있다. 본고에서는 정리의 유도 과정에서 얻어지는 실험 이론과 함께 디지털 오실로스코 프를 이용해서 이 정리를 시현시키는 방법을 소개한다. 1930년대에 소개된 정리를 다시 재조명하려는 이유는, 비록 정리가 오래 전에 소개되었다고는 할지라도 구체적인 유도 과정이나 물리 분야와 관련된 내용들은 우리에게는 여전히 잘 알려져 있지 않기 때문이다. 유도 과정에서 교류 복소 총저항(Impedence) $Z$, 역율(Power Factor), 위너 분광곡선의 확장된 물리적 의미와 함께, 나아 가, 흑체 복사에서 플랑크(M. Planck)의 양자화에 대한 배경이 자연스럽게 나타나므로, 일반물리학, 현대물리학, 분광학 및 물성 실험 등과 관련된 강의에 참고가 될 수 있다고 생각된다.
\end{abstract}

Keywords: 위너-킨친 정리, 디지탈 오실로스코프, 시현, 위너 분광 곡선

OCIS codes: (000.2060) Education; (000.2190) Experimental physics; (000.2658) Fundamental tests

\footnotetext{
${ }^{\dagger}$ E-mail: smjung@dau.ac.kr

Color versions of one or more of the figures in this paper are available online.
} 


\section{I. 서 론}

1930년대에 소개된 위너-킨친(Wiener-Khinchin) 정리는 어 떤 신호의 자기상관 함수의 푸리에(Fourier) 변환은 곧 그 신 호의 일율 분광띠에 해당된다는 것으로, 현재의 분광학, 물 성학 및 전기 통신 공학 분야에서 기초적으로 매우 중요한 정리 중의 하나이지만, 우리의 학부 과정에서는 아직 잘 소 개되고 있지 않은 내용이다. 그 이유는 여러 가지가 있겠지 만, 이 정리가 공학 분야에서 먼저 소개되었다는 점과 디지 탈 장비가 소개되기 이전에는 이 정리를 시현하기 위해 고가 의 상관기와 신호 처리 장비가 필요했던 점도 중요한 원인으 로 생각된다. 근래에 들어 디지털 공학이 발전됨에 따라 디 지털 오실로스코프가 일반화되고 있다. 이들에게는 이전의 애널로그 장치와는 달리 출력은 물론, 외부의 전산처리를 위 한 수치자료를 제공할 수 있을 뿐만 아니라, 대부분 자체에 가감승은 물론, 미분, 적분, 푸리에 변환 등의 각종 연산기능

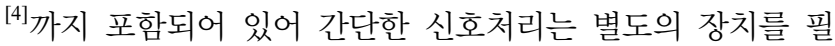
요로 하지 않으므로 정리의 시현을 저 비용으로 실현시키기 에 적당한 장치이다.

본 실험은 이와 같은 디지털 오실로스코프의 기능을 빌어 개인용 컴퓨터와 함께 위너-킨친 정리를 교실이나 실험실에 서 간단히 시현해 보이는 것이다. 오래 전에 발표된 정리를 재조명하려는 또 다른 이유는, 비록 정리가 오래 전에 소개 되었다고는 할지라도, 실험 이론이 정리의 유도 과정에서 직 접 얻어질 뿐만 아니라, 유도 과정을 통해, 잘 알려져 있지 않은 물리 분야와 관련된 내용들은 확인해 볼 수가 있기 때 문이다. 즉, 일반 물리학의 교류 복소 총저항 $Z$ 가 교류 입력 에 대한 계의 반응 함수임을 보게 되고, 교류 전력에서 소개 되는 역율은 반응계의 입력 지연 효과에서 비롯되며, 입력의 자기 상관 함수가 일율 분광곡선, 즉 위너 분광곡선에 대응 하고, 분광 곡선의 면적은 입력 신호의 일율과 같음을 보게 된다. 또한 연속 함수인 단순 조화진동을 푸리에 변환하면 불 연속인 델타 함수형의 충격(Impulse) 펄스가 된다는 사실로부 터 흑체 복사론에서 플랑크에 의한 정상 파동의 양자화 과정 에 관한 이해는 물론, 양자 역학에 관한 보다 깊은 이해를 얻을 수 있다.

\section{II. 이론적 배경}

\section{1. 선형계의 반응}

전기 통신 공학에서 계의 반응은 $f(t)$ 를 입력, $h(t)$ 를 계의 (충격) 반응함수, $g(t)$ 를 출력이라 할 때 다음과 같이 정의된 다(그림 1).

$$
g(t)=f(t) \otimes h(t)=h(t) \otimes f(t)
$$

식 (1)에서 $f(t)$ 와 $h(t)$ 는 서로 교환될 수 있으며, 식은 출력 $g(t)$ 는 계에 입력된 신호 $f(t)$ 가 계와의 반응 $h(t)$ 에 의한 결과 임을 말한다. 또한 반응함수 $h(t)$ 는, $h(t)$ 의 푸리에 정변환을 $H(\omega)$ 라 할 때, 다음과 같이 정의된다. 식에서 $F T$ 와 IFT는 각 각 푸리에 변환과 역변환을 가리킨다.

$$
h(t)=\operatorname{IFT} T H(\omega)]=\frac{1}{\sqrt{2 \pi}} \int_{-\infty}^{+\infty} H(\omega) e^{j \omega t} d \omega
$$

계의 함수 $H(\omega)$ 는 일반적으로 복소수이므로 다음과 같이 쓸 수 있다.

$$
H(\omega)=F T[h(t)]=\frac{1}{\sqrt{2 \pi}} \int_{-\infty}^{+\infty} h(t) e^{-j \omega t} d t=R+j X(\omega) \equiv Z(\omega) e^{j \phi(\omega)}
$$

식 (3)에서 $Z(\omega)$ 는 복소 진폭이며, $\Phi(\omega)$ 는 복소수의 실수 부 $R$ 과 허수부 $X(\omega)$ 사이의 편각으로써 회전 방향을 고려하 여 - $\theta(\omega)$ 로 나타낼 수도 있다. 한편 식 (2)과 같은 방식으로 $f(t)$ 를 푸리에 역변환으로 나타내면

$$
f(t)=\operatorname{IFT}[F(\omega)]=\frac{1}{\sqrt{2 \pi}} \int_{-\infty}^{+\infty} F(\omega) e^{j \omega t} d \omega
$$

$f(t)$ 의 정변환을 식 (3) 처럼 나타내면

$$
F(\omega)=F T[f(t)]=\frac{1}{\sqrt{2 \pi}} \int_{-\infty}^{+\infty} f(t) e^{-j \omega t} d t \equiv A(\omega) e^{j \psi(\omega)}
$$

식 (6)에서 $A(\omega)$ 는 식 (3)의 $Z$ 와 유사한 어떤 복소 진폭함수 이고, $\psi$ 는 식 (3)의 $\Phi$ 와 같이 복소 편각이다. 따라서 식 (2) 과 식 (4)의 도움으로 식 (1)은 다음과 같이 쓸 수 있다.

$$
g(t)=\operatorname{IFT}[F(\omega) \otimes H(\omega)]=\frac{1}{\sqrt{2 \pi}} \int_{-\infty}^{+\infty} F(\omega) H(\omega) e^{j \omega t} d \omega
$$

만일 $G(\omega)$ 를 $g(t)$ 의 푸리에 변환이라 하면 식 (6)은 다음 표현과 동등해진다.

$$
g(t)=\operatorname{IFT}[F(\omega) \otimes H(\omega)]=\operatorname{IFT}[G(\omega)]=\frac{1}{\sqrt{2 \pi}} \int_{-\infty}^{+\infty} G(\omega) e^{j \omega t} d \omega
$$

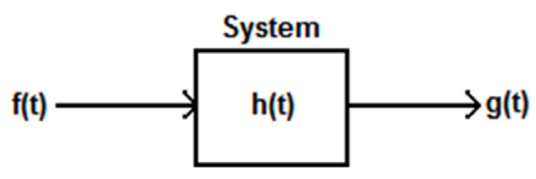

FIG. 1. Input and output of a linear system. 
여기서 식 (1)과 식 (7)의 연산 부호는 결국 복소 연산을 의 미하므로, 반드시 표기하지 않아도 무방하다.

만일 계가 이상적인 필터와 같이 $Z(\omega)$ 가 각진동수에 무관 하게 일정하고 위상 편기가 시간에 대해 선형인 어떤 계를 생각하면, 계의 위상편기가 일정할 때 일정한 각진동수 구간 내에서 어떤 시간 상수 $\tau$ 에 대해 식 (3)에서 $Z(\omega) \rightarrow Z_{o}, \Phi(\omega)$ $\equiv \Phi_{o}(\omega) \rightarrow \omega \tau$ 라고 둘 수 있으므로, 식 (6)은

$$
\begin{aligned}
g(t) & =\frac{1}{\sqrt{2 \pi}} \int_{-\infty}^{+\infty} G(\omega) e^{j \omega t} d \omega=\frac{1}{\sqrt{2 \pi}} \int_{-\infty}^{+\infty} Z_{o} e^{j \omega \tau} F(\omega) e^{j \omega t} d \omega \\
& =\frac{Z_{o}}{\sqrt{2 \pi}} \int_{-\infty}^{+\infty} F(\omega) e^{j \omega(t+\tau)} d \omega=Z_{o} f(t+\tau)
\end{aligned}
$$

식에서 선형계와 함께 도입된 어떤 시간 상수 $\tau$ 를 전기 통신 공학에서는 보통 지연 시간(delay time)이라 부르며, 이 식은 계에 어떤 신호 $f(t)$ 가 입력될 때 그 계는 입력 신호 파형에 서 $Z_{o}$ 배 만큼 증가되고 $\tau$ 시간 만큼 경과된 파형을 출력함 을 말한다. 식 (3)에서 $\Phi(\omega)$ 대신 - $\theta(\omega)$ 가 사용될 경우에는 $\omega \tau$ 가 되어서 $g(t)=Z_{\mathrm{o}} f(t-\tau)$ 가 된다. 만일 계가 특성상 매 순간 의 입력 신호를 $\tau$ 만큼 지연시킨다면, 계의 출력 파형은 입 력 파형과 비동기 상태에 있게 된다. 이 때문에 현대의 오실 로스코프들에는 사전 트리거(Pre-Trigger) 기능이 포함되어 있다. 식 (8)은 보통 시간 편기(Time Shifting) 정리 ${ }^{[5]}$ 라고 불 린다.

식 (8)의 활용 예로써, $f(t)$ 를 임의 위상 $\Phi_{o}=\omega_{o} t_{o}$ 를 가진 어 떤 교류 정전류 입력 $f(t) \equiv i_{a c}(t)=i_{\mathrm{p}} \exp \left[j \omega_{o}\left(t+t_{o}\right)\right]$ 로 생각하면, 그 푸리에 변환 $F(\omega) \equiv I_{a c}(\omega)$ 는

$$
\begin{aligned}
I_{a c}(\omega) & =\frac{i_{p} e^{j \omega_{o} t_{o}}}{\sqrt{2 \pi}} \int_{-\infty}^{+\infty} e^{j \omega_{o} t} \cdot e^{-j \omega t} d t \\
& =\frac{i_{i} e^{j \omega_{o} t_{o}}}{\sqrt{2 \pi}} \int_{-\infty}^{+\infty} e^{-j\left(\omega-\omega_{o}\right) t} d t=i_{p} e^{j \omega_{o} t_{o}} \cdot \delta\left(\omega-\omega_{o}\right)
\end{aligned}
$$

식 (9)는 주기적 전류 입력의 푸리에 변환은 $\omega=\omega_{o}$ 일 때만 값 이 존재하는 델타 함수의 $i_{\mathrm{p}} \exp \left[\omega_{0} t_{0}\right]$ 배인 충격 펄스(Impulse) 와 동등함을 의미한다. 이 것은 시간 축에서 표시된 어떤 연 속 주기 신호는 축과 일정 편각을 이룬 각진동수 축 상에서 는 불연속적인 델타 함수 신호로 보인다는 점이다. 예는 비 록 진행파에 관한 것이지만, 서로 반대 방향으로 진행하는 두 진행파의 보강 간섭 결과가 정상파이므로 정상파에 관한 결과도 얻을 수 있다. 이 점은 플랑크의 흑체 복사론에서 양 자화 가정의 동기가 될 수 있다. 이제 식 (9)의 표현을 식 (7) 에 사용하면

$$
G(\omega)=H(\omega) I_{a c}(\omega)=H(\omega)\left[i_{p} \cdot e^{j \omega_{o} t_{o}} \cdot \delta\left(\omega-\omega_{o}\right)\right]
$$

식 (10)을 푸리에 역변환하면

$$
\begin{aligned}
g(t) & =\operatorname{IFT}[G(\omega)]=\operatorname{IFT}\left[H(\omega) I_{a c}(\omega)\right] \\
& =\operatorname{IFT}\left[H(\omega)\left[i_{p} \cdot e^{j \omega_{o} t_{o}} \cdot \delta\left(\omega-\omega_{o}\right)\right]\right] \\
& =i_{p} \cdot e^{j \omega_{o} t_{o}} \cdot \operatorname{IFT}\left[H(\omega) \cdot \delta\left(\omega-\omega_{o}\right)\right] \\
& =i_{p} \cdot e^{j \omega_{o} t_{o}} \cdot \operatorname{IFT}\left[H\left(\omega_{o}\right) \cdot \delta\left(\omega-\omega_{o}\right)\right] \\
& =i_{p} \cdot e^{j \omega_{o} t_{o}} \cdot H\left(\omega_{o}\right) \cdot \operatorname{IFT}\left[\delta\left(\omega-\omega_{o}\right)\right] \\
& =i_{p} \cdot e^{j \omega_{o}\left(t+t_{o}\right)} \cdot H\left(\omega_{o}\right) / \sqrt{2 \pi}=i_{a c}(t) \cdot H\left(\omega_{o}\right) / \sqrt{2 \pi}
\end{aligned}
$$

식 (11)에서 세 번째 등호의 관계는 델타 함수의 성질을 이 용한 것이다. 여기서 식 (11)의 형태를 $v_{a c}=i_{a c} Z$ 와 비교해 보면, $Z$ 가 바로 계의 함수 $H(\omega) / 2 \pi$ 에 대응되어야 하는데, 이 점은 각진동수 $\omega_{o}$ 인 앞서의 교류 정전류 $i_{a c}(t)$ 에 대해 $Z$ 를 계 의 함수로써 적용해보면 곧 알 수 있다. : 어떤 회로에 대해 $H\left(\omega_{o}\right) / \sqrt{2 \pi} \equiv Z_{o}$ 라 두면, 식 (11)은

$$
g(t)=i_{a c}(t) Z_{o}
$$

식 (12)에서 두 번째 항은 계의 출력 전압이므로, $g(t)$ 는 교류 출력 전압 $v_{a c}(t)$ 에 해당되어 $Z_{o}$ 가 곧 계의 함수가 되어야 함 을 알 수 있다. 이와는 달리, 입력이 교류 정전압이었다면, $H\left(\omega_{0}\right) / \sqrt{2 \mathrm{p}}=1 / Z_{o}=Y$ 가 되고 $g(t)$ 는 전류에 대응되어야 할 것 이다. 앞에서 $Y$ 는 전기공학에서 어드미턴스(Admittance)라고 불리는 량이다.

\section{2. 위너-킨친 정리와 일율 분광 곡선}

어떤 선형계에 신호 $f(t)$ 가 입력되면 계로부터 출력은 식 (8) 과 같다. 이 식의 양변에 $f^{*}(t)$ 을 곱한 다음 어떤 시간 $T$ 에 대 해 평균하면서 식 (8)을 참고하면, 그 일반 표현은

$$
\begin{gathered}
\lim _{T \rightarrow \infty} \frac{1}{2 T} \int_{-T}^{T} f^{*}(t) g(t) d t=\lim _{T \rightarrow \infty} \frac{Z_{o}}{2 T} \int_{-T}^{T} f^{*}(t) f(t+\tau) d t \\
=\lim _{T \rightarrow \infty} \frac{Z_{o} e^{j \omega \tau}}{2 T} \int_{-T}^{T} f^{*}(t) f(t) d t=\lim _{T \rightarrow \infty} \frac{h_{o}}{2 T} \int_{-T}^{T}|f(t)|^{2} d t
\end{gathered}
$$

여기서 식 (1)과 식 (8)을 참고하면서 식 (13)의 두 번째와 세 번째 항을 비교해 보면, $Z_{o} \exp [j \omega \tau]=h_{o}$ 임을 알 수 있다. 또한 $T \rightarrow \infty$ 이면 신호가 직류에 해당되므로, 교류에 대해서는 어 떤 유한한 $T$ 의 극한이 필요함도 알 수 있다. 이 유한한 극한 은 보통 주기 신호에서 그 주기가 선택된다.

식 (13)의 의미는 $f(t) \rightarrow i(t), h_{0} \rightarrow Z, g(t) \rightarrow v(t)$ 로 치환해 보면, 바로 계에 의해 소비되는 한 주기 당 평균일율 표현임을 알 수 있으며, $h_{o}$ 에서 $|\exp (j \omega \tau)|<1$ 이므로, 전원에서 공급된 일 율은 계에 의한 지연효과 때문에 $\exp (j \omega \tau)$ 의 실수부가 $\cos [\omega$ $\tau]$ 만큼 감소됨도 알 수 있다. 이 $\cos [\omega \tau]$ 는 교류 신호의 일율 
에서 역율로 알려져 있다.

식 (13)의 첫 째 적분의 피적분 함수는 입력과 출력에 관한 교차상관(Crosscorrelation) 함수라 불리는 것이며, 두 번째 적분에서 피적분 함수는 $f(t)$ 의 자기상관 함수라 불린다. 교 차 상관은 어떤 해석적인 입력 신호가 계에 입사될 경우에 그 출력 신호와의 상관 관계를 의미한다. 한편, 식 (13)에서 $h_{o}=Z_{o} \exp [j \omega \tau]$ 이며, 시간 편기 정리와 파시벌(Paseval) 정리 ${ }^{[6]}$ 의 도움으로, $A(\omega)$ 를 어떤 실수 진폭함수라 할 때, 식 (5)에 서 $|F(\omega)|^{2}=|A(\omega)|^{2}$ 이므로, 만일 $Z_{o} \exp [\omega \tau]|A(\omega)|^{2} / 2 T \equiv W(\omega)$ 로 둔다면, 일율의 분광 곡선은 위너 분광 곡선 $W(\omega)$ 와 동일해 짐을 알 수 있다. 이 과정을 요약하면 다음과 같이 쓸 수 있다.

$$
\begin{gathered}
\lim _{T \rightarrow \infty} \frac{Z_{o}}{2 T} \int_{-T}^{T} f^{*}(t) f(t+\tau) d t=\lim _{T \rightarrow \infty} \frac{Z_{o}}{2 T} \int_{-T}^{T}|f(t)|^{2} e^{j \omega \tau} d t \\
\frac{Z_{o}}{4 \pi T} \int_{-\infty}^{\infty}|A(\omega)|^{2} e^{j \omega \tau} d \omega=\frac{1}{2 \pi} \int_{-\infty}^{\infty} W(\omega) d \omega
\end{gathered}
$$

이로써 위너-킨친 정리는 증명되며, 한 입력 신호에 대한 자기 상관함수를 다시 푸리에 변환시킨 결과가 곧 위너 분광 곡선에 대응함을 알 수 있다. 식 (14)에 의하면 위너 분광 곡 선은 자기 상관함수와도 관련되므로, 적당한 주기적 입력 신 호와 지연 수단 및 푸리에 변환 과정이 제공된다면 정리의 시현도 가능함을 시사하고 있다.

식 (14)의 사용 예로써, 앞에 언급된 교류 정전류 신호 $f(t)$ $\equiv i(t)=i_{\mathrm{p}} \exp \left[j \omega_{0}\left(t+t_{0}\right)\right]$ 에 대해, 복소 공액인 $f^{*}(t)=i^{*}(t)=i_{\mathrm{p}} \exp [-j$ $\left.\omega_{o}\left(t+t_{o}\right)\right]$ 을 곱한 다음, $f(t+\tau) \equiv i_{a c}(t+\tau)=i_{a c}(t) \exp \left[j \omega_{o} \tau\right]$ 임을 고 려해서 한 주기 $T$ 에 대해 적분을 하면,

$$
\begin{aligned}
\frac{1}{2 T} \int_{-T}^{T} f^{*}(t) g(t) d t & =\frac{Z_{o}}{2 T} \int_{-T}^{T} f^{*}(t) f(t+\tau) d t \\
& =\frac{Z_{o} e^{j \omega_{o} \tau}}{2 T} \int_{-T}^{T} i_{a c}^{*}(t) i_{a c}(t) d t \\
& =\frac{h_{o}}{T} \int_{0}^{T}\left|i_{a c}(t)\right|^{2} d t=\frac{h_{o} i_{p}^{2}}{T} \int_{0}^{T} d t=h_{o} i_{p}^{2}
\end{aligned}
$$

식 (15)에서 한 주기 당 일율은 $h_{o} i_{p}{ }^{2}$ 로, $h_{o}=Z$ 로 두면 앞에서 다룬 일율의 정의와 동일함을 볼 수 있다. 여기서 $\tau=0$ 이면 전압과 전류가 동위상이지만 $\tau \neq 0$ 인 경우에는 역율이 존재 해서 에너지의 손실이 발생한다. 또한 두 번째 적분에서 두 신호의 곱의 출력 주파수는 두 신호의 주파수가 동일하므로 두 배가 됨도 알 수 있다.

이제 식 (9)를 제곱하면

$$
|I(\omega)|^{2}=i_{p}^{2} \cdot e^{j \omega_{o} \delta} \cdot\left[\delta\left(\omega-\omega_{o}\right)\right]^{2}
$$

적분에서 $A(\omega)$ 대신 $I(\omega)$ 를 대입하면, 식 (14)은 다음과 같이 쓸 수 있다.

$$
\frac{Z_{o}}{4 \pi T} \int_{-\infty}^{\infty}|I(\omega)|^{2} d \omega=\frac{Z_{o} i_{p}^{2}}{4 \pi T} \int_{-\infty}^{\infty}\left[\delta\left(\omega-\omega_{o}\right)\right]^{2} d \omega=\frac{1}{2 \pi} \int_{-\infty}^{\infty} W(\omega) d \omega
$$

식 (17)의 두 번째 항에서 델타 함수를 $\operatorname{sinc}$ 함수 $^{[7]}$ 에 대응 시키면 식의 두 번째 적분은

$$
\begin{gathered}
\frac{h_{o} i_{p}^{2}}{4 \pi T} \int_{-\infty}^{\infty}\left[\delta\left(\omega-\omega_{o}\right)\right]^{2} d \omega=\frac{h_{o} i_{p}^{2}}{2 \pi T} \int_{0}^{\infty} T\left(\frac{\sin [\omega T / 2]}{\omega T / 2}\right)^{2} d \omega \\
=\frac{h_{o} i_{p}^{2}}{2 \pi} \int_{0}^{\infty}\left(\frac{\sin [\omega T / 2]}{\omega T / 2}\right)^{2} d \omega=\frac{h_{o} i_{p}^{2}}{2 \pi}
\end{gathered}
$$

$\operatorname{sinc}$ 함수의 제곱은 적분값이 1 이며, 적분 결과는 다시 식 (17) 의 세 번째 항과 같아야 하므로

$$
\frac{1}{2 \pi} \int_{0}^{\infty} W(\omega) d \omega=\frac{h_{o} i_{p}^{2}}{2 \pi} \rightarrow \int_{0}^{\infty} W(\omega) d \omega=h_{o} i_{p}^{2}
$$

식 (19)는 분광 곡선 아래의 면적이 신호의 일율 $h_{o} i_{p}^{2}$ 과 같아 야 함을 나타내고 있다.

식 (14)에서 피적분 함수들 사이의 관계와 적용 예로부터, 위너-킨친 정리를 시현해 보이려면, 신호 발생기와 신호 지 연 기능 외에도 신호 승과 푸리에 변환 기능을 보유하고 있 는 신호 처리 장치가 필요함을 알 수 있다.

\section{III. 실 험}

그림 2는 정리를 시현하기 위한 장치도이다. 신호발생기 (흥창, $\mathrm{G} 305$, 한국)에 의해 발생된 신호는 주파수가 $1.03 \mathrm{kHZ}$ 인 삼각함수 파로써 출력단에 연결된 $\mathrm{BNC} \mathrm{T}$ 단자에 연결된 동축선에 의해 디지털 오실로스코프(Agilent, HP54622A, USA) 의 채널 1 과 2 로 입력된다. 입력 신호는 실험 이론상 정전류 원이 요구되지만, 동축선의 종단이 개방 상태이고 신호 발생 기의 동작이 안정적이라면, 실험 목적상 필수 사항은 아니다. 필요하다면 수 십 $\mathrm{k} \Omega$ 정도의 저항을 신호 동축선에 직렬로 연결해서 사용할 수 있다. 신호의 동기는 1 채널에 입력되는 신호에 의해 이루어지며, 2 채널은 지연 시간 설정 다이얼을 돌려 적당한 값이 되도록 한다. 본 실험에서는 $1 \mu \mathrm{sec}$ 로 설 정되었다. 하지만 이 값은 신호가 오실로스코프에서 설정된

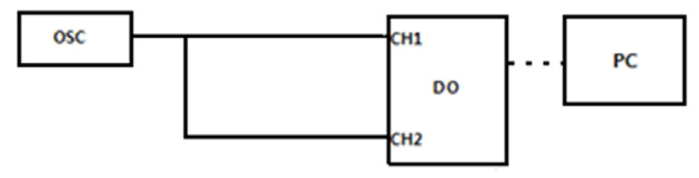

FIG. 2. Experimental set-up. 
지연 시간일 뿐이며, 신호 발생기로부터 오실로스코프까지 신호를 전달하는 동축선에 의한 지연값은 아니므로 신호의 알짜 지연 시간을 정하는 데는 유의해야 한다. 이 점은 학부 실험에서 일반적으로 당면될 수 있는 조건이지만, 알짜 지연 시간을 알 수 없다면 $h_{o}$ 의 값을 결정하기가 곤란해지므로, 이론적인 일율값은 사전에 예상하기가 곤란해진다. 이 경우 에는 위너 분광띠로부터 직접 구한 일율값에 의존할 수 밖에 없다.

신호가 화면에 표시되면, 트리거 다이얼을 돌려 신호가 안 정하게 표시되도록 한 다음에 신호 입력을 중지시키고 화면 을 포착해서 그 자료들을 오실로스코프에 내장된 플로피 디 스크에 그림 또는 Excel 파일(CSV)로 저장해 둔다. 그 다음 은 기능키를 사용해서 두 신호를 곱한 다음 이를 저장한 후 곱해진 신호에 대해 적분과 $\mathrm{FFT}$ 를 각각 실행시키고 이 결과 를 다시 저장시킨다. 이렇게 저장된 파일을 개인용 컴퓨터의 엑 셀에서 불러와 다시 그리면 위너 분광 곡선을 얻을 수 있다.

\section{VI. 결과 및 논의}

그림 3과 4에 입력 및 출력 신호와 입력 신호의 푸리에 변 환 결과가 나타나 있다. 그림 3에서 신호 파형이 깨끗하게 보이지 않는 점은 디지털 장비의 특징이다. 그림 3에서 출력 신호의 푸리에 변환 결과는 신호 세기만 무시될 수 있을 만 큼 다를 뿐 입력 신호와 동일하므로 따로 제시되지 않았다. 그림 3의 두 조화 함수 파형 중에서 회색선은 입력 신호로써 오실로스코프의 채널 1 에 입력된 것이고, 흑색선은 $1 \mu \mathrm{sec}$ 정 도로 지연 설정된 것으로써, 채널 2에 입력된 것이다. 이 지 연 상태는 오실로스코프의 화면 상에서 알 수 있으나, 본 실 험에서는 화면을 직접 인용하기가 곤란한 상태라서 Excel에 서 결과를 구했다(그림에서 두 신호를 구별하기 위해 선의
굵기를 다르게 했음.). 따라서 $\mathrm{kHZ}$ 대역에서 $\mathrm{MHZ}$ 급의 지연 차이는 나타나지 않으므로 두 신호가 동일해 보인다. 두 신 호 모두 최대 전압은 $\pm 1.7 \mathrm{~V}_{\mathrm{p}}$ 이며, 주파수는 $1.03 \mathrm{kHZ}$ 이다. 그림 4 는 채널 1 의 입력 신호와 채널 2 의 출력 신호를 곱 한 결과이다. 거의 동일한 두 신호가 곱해진 결과이므로 파 형은 대체로 유지되고 있으나 깨끗하지는 않다. 최대 전압은 $\pm 2.9 \mathrm{~V}_{\mathrm{p}}$ 정도임을 볼 수 있다. 그림 5는 신호와 관련된 값들 을 읽기가 용이하도록 하기 위해 그림 4 의 신호를 적분한 결 과이다. 이 결과는, 사실상 오실로스코프에 의한 제한이 없 다면, $T \rightarrow \pm \infty$ 에 관한 적분 결과를 보여준다고 할 수 있다. 그림 4와 비교해 보면, 적분 과정을 통해 파형이 단순해져 있어 축과의 교차점을 보다 용이하게 결정할 수 있음을 알 수 있다. 그림 3에서와 같이 입력 신호를 최대한 기준 트리거 위치로부터 좌우 대칭이 되도록 설정해 두면, 주기는 Excel에 의해 원점 부근의 $\mathrm{x}$ 축을 통과하는 추세선과 신호 곡선과의 교차점으로부터 대략적으로 확인해 볼 수 있다. 그림에서 주 기는 첫 째 교차점으로부터 1 상한의 두 번째 교차점까지의 소요 시간으로 대략 $0.48 \mathrm{~ms}$ 정도임을 볼 수 있다. 주파수로 환산하면, 두 신호의 곱은 입력 신호 주파수의 2 배에 해당 된다. 추세선의 구배는 대략 $1.7 \mathrm{~V}$ 정도임을 알 수 있다. 이 값은 두 신호 진폭을 곱한 값의 제곱근에 해당하며, 입력 신 호의 진폭과 거의 동일하다(그림 2).

그림 6은 그림 4의 신호곱을 푸리에 변환한 결과로써 위너 분광 곡선에 해당된다. 두 그림에서 첫 째는 변환 결과이고, 두 번째 그림은 Excel에 의해 세기가 양의 값을 가지는 정점 부분만을 확대한 것으로, 그림에서 파형이 좋아 보이지는 않 지만, 분명히 주파수가 $2 \mathrm{kHZ}$ 부근에서 최대의 정점을 발견 할 수가 있다. 파형은 주파수 소인 대역을 증가시킬수록 측 정과 관련된 고조파 성분들에 관한 작은 세기의 봉우리들이 나타나면서 개선된다(그림에서는 이들이 소인 대역 외부에

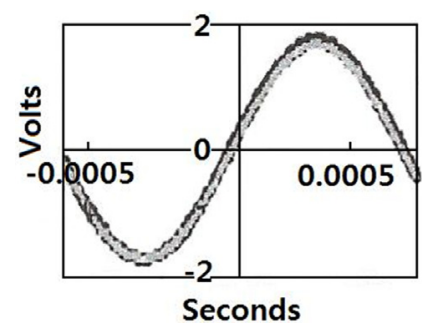

FIG. 3. Input (grey) and output (black).

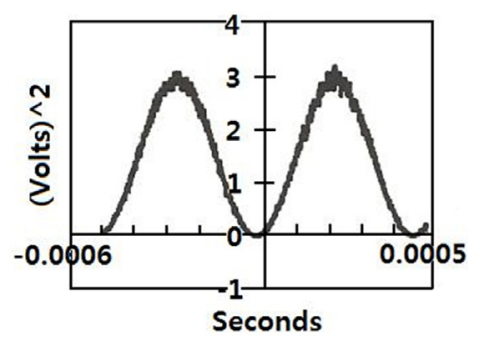

FIG. 4. Product of input and output.

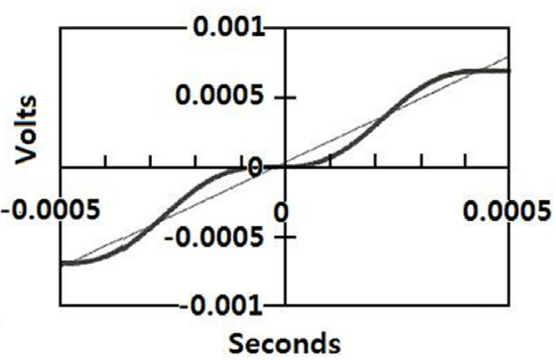

FIG. 5. Integration of FIG. 4
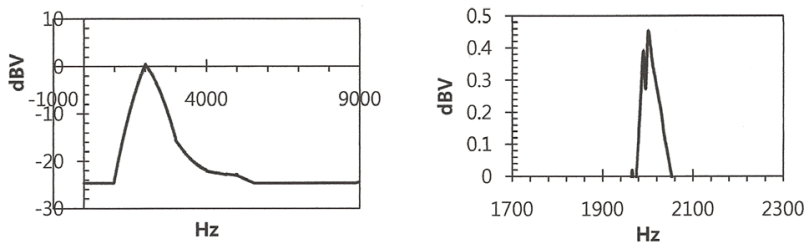

FIG. 6. Fourier transform of FIG. 4 (Offset:15 dB) and enlargement of its peak area (Wiener spectrum). 
있어 화면에는 나타나지 않는다). 전체 곡선의 모습이 실제 로는 델타 함수의 푸리에 변환형인 sinc 함수와도 유사하지 않으며, 또 날카롭지 않은 점은 주로 데이터의 각 점들 사이 의 연결 기능 때문으로 보이는데, 전체 소인대역 중에서 좁 은 일부 구간만을 표시함으로써 데이터 점들 사이의 간격이 확장되었기 때문으로 보인다.

위너-킨친 정리에 의하면 곡선 아래의 면적이 신호의 일 율에 대응되어야 하는데, 실제 변환에서 얻어지는 결과는 처 음 그림과 같이 최대 세기가 $0 \mathrm{dBV}$ 부근에 있고, 이하의 부분 은 모두 음의 영역에서 나타난다. 음의 영역에 있는 부분은 푸리에 변환 과정에서 발생되는 기저 잡음에 속하는 것으로 써 순수 신호와는 무관해 보이며, 식 (14)과 식 (15)에 부합 되지 않는 결과이다. 뿐만 아니라, 그래프의 모습 자체도 수 집된 자료점들 사이를 내삽으로 연결한 것이므로, 주파수 축 상에서 일정한 폭을 가지게 된다. 이 점은 이상적인 신호에 의해 기대되는 것과는 다른 결과이다. 그러므로 이들에 의한 영향은 일율 계산에서 고려되어야 한다.

그래프에서 일율의 계산에 관련되는 부분은 두 번째 그림 에서 양의 세기 영역에 있는 근사 삼각형 부분만으로, 세 개의 봉우리를 볼 수 있다. 제일 작은 봉우리의 발생 원인은 정확 히 알 수는 없으나 샘플링이나 푸리에 변환 과정에서 나타난 불필요한 성분으로 추정된다. 나머지 두 봉우리는 입력 신호 성분과 신호선의 임피던스 불일치로 인한 반사파로 생각된다. 두 봉우리를 하나의 이등변 삼각형으로 취급하고 $\operatorname{sinc}$ 함수로 근사해서 대략의 일율값을 반폭치로 계산해 보면, 밑변이 약 $80 \mathrm{HZ}$ 정도이고, 반폭치는 $60 \mathrm{HZ}$ 정도이며, 세기가 0.48 $\mathrm{dBV}$ 이므로, 약 $28.8 \mathrm{dBV} \cdot \mathrm{HZ}$ 이다. 이 값의 단위를 $\mathrm{V} \cdot \mathrm{ms}$ 로 바꾸어 보면, 대략 $18.37 \mathrm{~V} \cdot \mathrm{ms}$ 이다. 반폭치의 대역 속에 16.7 개의 주기 파동이 통과했으므로, 한 주기 당 대략 $1.1 \mathrm{~V} \cdot \mathrm{ms}$ 의 에너지가 공급된 셈이다. 이상적으로 생각할 때 하나의 입 력 신호는 한 주기 당 $1.7 \mathrm{~V} \cdot \mathrm{ms}$ 의 에너지를 공급하는 셈이 므로 이 값과는 차이가 있다. 이 사실은 주로 봉우리들의 면 적을 하나의 이등변 삼각형으로 근사한 점에서 비롯된 것으 로 생각되며, 보다 정확한 결과를 얻으려면 주파수가 안정된
고급 신호 발생기를 사용하고, 임피던스 정합조치가 필요할 것으로 생각되지만, 이들을 사용할 경우에는 실험 내용 대 비용이 크게 증가되며, 특히 후자의 경우는 보통 신호 진폭 의 감쇠가 너무 크므로 오히려 불편할 경우가 많을 것으로 생각된다.

\section{V. 결 론}

위너-킨친 정리를 증명과 함께 개인용 컴퓨터와 디지털 오 실로스코프로 간단히 시현시킬 수 있었다. 특히 실험 이론을 위한 정리의 유도 과정에서 교류 회로의 임피던스 $Z$ 가 교류 신호에 대한 계의 반응 함수의 푸리에 변환 결과이며, 역율 은 계의 신호 지연 효과에서 비롯된다는 사실이나, 단순 조 화 신호의 푸리에 변환이 델타 함수형의 충격 펄스에 대응된 다는 사실은 플랑크가 흑체 복사론에서 정상파 에너지를 양 자화한 것을 정당화시키며, 기존의 학부 물리 교육에 참고가 될 수 있을 것으로 생각된다.

\section{References}

1. L. Levi, Applied Optics (John-Wiley \& Sons, Inc., NY, USA, 1968), vol. 1, Chapter 3, pp. 138-140.

2. http://en.wikipedia.org/wiki/Wiener-Khinchin_theorem.

3. http:/gmrt.ncra.tifri.res.in/gmrt_hpage/Users/doc/WEBLF/L FRA/node 7.html.

4. Agilent, HP54622A User Manual, (Agilent Technology, C.S., 2000), Chapter 5.

5. A. Papoulis, The Fourier Integral and its Applications (McGrawHill, NY, USA, 1962), Chapter 5, p. 86.

6. A. Papoulis, The Fourier Integral and its Applications (McGrawHill, NY, USA, 1962), Chapter 1, p. 27.

7. R. A.Gabel and R. A. Roberts, Signals and Linear Systems (John Wiley \& Sons, Inc., NY, USA, 1973), Chapter 5, pp. 233-257. 